\title{
Strategy operationalization in a Taekwondo Federation
}

\author{
Pedro SOBREIRO*1,3, José SOUSA¹, Hugo LOUR01,2,3, \& Ana CONCEIÇÃ 01,2,3 \\ ${ }^{1}$ Sports Sciences School of Rio Maior - Polytechnic Institute of Santarém (Portugal) \\ ${ }^{2}$ Centro de Investigação em Desporto, Saúde e Desenvolvimento Humano (CIDESD) (Portugal) \\ ${ }^{3}$ Centro de Investigação em Qualidade de Vida (CIQV) (Portugal)
}

\section{Introduction}

The management of sport requires addressing the organization structures and systems, considering simultaneously critical environmental issues, challenges to decision-making, demands from multiple stakeholders, the changing environment and board leadership. The lacks of management resources that the sports organizations have develop their strategy in opposition to their corporate counterparts (Ferkins, Shilbury, \& McDonald, 2005), the need for studies addressing the strategy operationalization in sport organizations (Slack, 2010), and the difficulties to transfer human resources management practices, from complex business organizations to non-profit sport organizations (Taylor \& McGraw, 2006). The challenge to address several elements developing the sport organization strategy underlies the fruition of this study, which aims to facilitate the assessment of the strategy and the correspondent improvement actions in a Martial Art and Combat Sport Federation (MACSF), according its business objectives and business capabilities.

\section{Methodology}

The study methodology was supported in the action-research involving a single case study, considering the inexistence of an action plan defining what the organization should develop to achieve its business objectives systematically. The research was developed in a MACSF where the study data collection was obtained through direct and participative observation. The information was inserted in a research instrument developed to support our proposed approach: (1) organization mission and vision; (2) identification of strategic objectives; (3) stakeholders analysis; (4) identification of business capabilities; (5) assessment of stakeholder concerns and objectives; (6) clarification of operational objectives aligned with stakeholders, business capabilities and strategic objectives; (7) prioritization of improvement areas and (8) definition of an action plan. The elements present in the interviews where: (1) President; (2) Secretary; (3) accounting officer; (4) sports director; and (5) accounting clerical. To allow a richer data gathering, the members present were informed to contribute according their experience and not in representation of the functional area where are working. Was used a computer to present the information being retrieved using a data show to facilitate the assessment and reflection.

\section{Results}

The results where the identification of the necessary improvement actions to be developed, according the MACSF objectives and its business capabilities, supported in the assessment of the concerns related to each stakeholders. Each concern to be solved requires the definition of an objective that should to be achieved to solve the concern. The concerns related to each stakeholder,

\footnotetext{
*Email: sobreiro@esdrm.ipsantarem.pt
} 
e.g. athletes where "Difficulty in control athletes not registered"; "Reduced participation in international competitions" and "Reduced number of athletes in the Olympic ranking" which allowed the identification of the improvement actions "Create advantages to registered athletes"; "Identify approaches and sponsors to develop initiatives to increase the involvement in these competitions" and "Develop more competitions to increase the participations of sport clubs and associations". The assessment of the improvement actions allowed the definition of 10 projects to support the achievement of the MACSF strategy.

\section{Discussion and conclusion}

Through adoption the action research, we were able to develop the assessment of the necessary improvement actions to achieve the strategy. The results show that the involvement of the organization responsible is fundamental. The interviewed should not be present in representation of a business function. The clarification of the mission simplifies the identification of the business capabilities and the clarification of the business capabilities allow to validate if the mission is properly defined. The inexistence of strategic objectives without the correspondent business objectives indicates the inexistence of objectives to support its operationalization, which represents also, the inexistence of an improvement action to support the achievement of a business objective. Our goal was to propose an approach that could be adopted in a sport organization, exploring the lack of research in strategy operationalization. The approach was developed in a MACSF, which allowed corroborating is appliance and assess the theoretical findings.

\section{References}

Ferkins, L., Shilbury, D., \& McDonald, G. (2005). The Role of the Board in Building Strategic Capability: Towards an Integrated Model of Sport Governance Research. Sport Management Review, 8(3), 195-225.

Slack, T. (2010). From the locker room to the board room: Changing the domain of sport management. JSM, 10(1).

Taylor, T., \& McGraw, P. (2006). Exploring Human Resource Management Practices in Nonprofit Sport Organisations. Sport Management Review, 9(3), 229-251.

Key words: Business strategy; operationalization; sport organization; improvement actions; martial arts; combat sports. 